\title{
Self-Medication Practice against Malaria and Associated Factors in the City of Parakou in Northern Benin: Results of a Population Survey in 2017
}

\author{
Cossi Angelo Attinsounon ${ }^{1,2 *}$, Yollande Sissinto ${ }^{3}$, Euripide Avokpaho ${ }^{3}$, Adébayo Alassani², \\ Majid Sanni' ${ }^{1}$ Marcel Zannou ${ }^{4}$
}

${ }^{1}$ Faculty of Medicine, CHUD-Borgou, Teaching and Research Unit of Infectious and Tropical Diseases, University of Parakou, Parakou, Bénin

${ }^{2}$ University of Parakou, CHUD-Borgou, Clinic of Internal Medicine, Parakou, Bénin

${ }^{3}$ University of Abomey Calavi, CNHU-HKM, Laboratory of Parasitology-Mycology, Cotonou, Bénin

${ }^{4}$ University of Abomey Calavi, CNHU-HKM, Clinic of Internal Medicine, Cotonou, Bénin

Email: *acosange@yahoo.fr

How to cite this paper: Attinsounon, C.A., Sissinto, Y., Avokpaho, E., Alassani, A., Sanni, M. and Zannou, M. (2019) Self-Medication Practice against Malaria and Associated Factors in the City of Parakou in Northern Benin: Results of a Population Survey in 2017. Advances in Infectious Diseases, 9, 263-275.

https://doi.org/10.4236/aid.2019.93020

Received: August 5, 2019

Accepted: September 15, 2019

Published: September 18, 2019

Copyright $\odot 2019$ by author(s) and Scientific Research Publishing Inc. This work is licensed under the Creative Commons Attribution International License (CC BY 4.0).

http://creativecommons.org/licenses/by/4.0/ c) (i) Open Access

\begin{abstract}
Introduction: Self-medication is a common practice in Benin. It has many consequences on people's health in general and develops chemoresistance in particular. Aim: The aim of this work is to study the practice of anti-malarial self-medication in the city of Parakou and to identify the associated factors with this practice. Methods: This was a descriptive cross-sectional analytical survey that took place in the period from April 15 to June 24, 2017. Adults who reported having had malaria symptoms in the last 6 months before the survey and living in 9 neighbourhoods randomly selected in the city of Parakou were included. A structured questionnaire collected their self-medication habit, the drugs used, the supply places and the reasons for this practice. Data were analysed using the Epi-data 3.1 software. Results: Of the 335 respondents included in this study, $141(42.09 \%)$ had self-medicated including 130 (38.81\%) with anti-malarial drugs. Fever is the main symptom of malaria cited by respondents ( $129 \%$ or $38.51 \%$ ) followed by headache $(93 \%$ or $27.76 \%)$. The most commonly used anti-malarial drugs for self-medication are quinine $(60 \%$ or $44.45 \%)$ followed by artemisinin-based combination therapy (46\% or $34.07 \%)$. Eighty-seven respondents (66.92\%) did not have a good knowledge of the drug dosage. Reasons for self-medication were mainly the high cost of consultation fees (99\% or 54.10\%) and good knowledge of one's illness (53\% or $28.96 \%$ ). Self-medication associated factors were fever ( $p$ $=0.04)$, non-prescription drugs supply in pharmacies $(\mathrm{p}<0.01)$, drugs supply
\end{abstract}


in the informal market $(\mathrm{p}<0.01)$, previous satisfactory use of the drug ( $\mathrm{p}<$ $0.01)$, drug cost availability $(\mathrm{p}=0.03)$ and drug recommendation by a relative or friend $(p=0.02)$. Conclusion: Self-medication is a common practice in the city of Parakou. Medicines purchased without prescription in pharmacies and drugs availability in street facilitate this practice, which may compromise the effectiveness of anti-malarial drugs.

\section{Keywords}

Self-Medication, Anti-Malarial Drugs, Urban Setting, Parakou, Benin

\section{Introduction}

Malaria is a parasitic disease caused by a Plasmodium genus protozoan transmitted to human beings by the female mosquito called anopheles. According to the Global Malaria Report in 2018, 219 million cases were recorded with 435,000 deaths worldwide in 2017. The WHO African Region alone accounts for $92 \%$ of malaria cases and $93 \%$ of deaths [1].

In Benin, according to the same report, approximately 1,904,495 cases were reported, including 1,573,165 cases in health facilities, 171,442 cases detected in community settings and 159,890 cases reported by private clinics. The number of deaths was 2182 [1].

One of the strategies for reducing malaria-related morbidity and mortality is rapid access to diagnosis with adequate and effective treatment [2] [3].

In several Benin rural areas, access to a health facility and/or qualified health workers is sometimes very difficult [4]. This situation exposes many patients to resort to either traditional healers or self-medication. Self-medication is a frequent and well-documented practice in the literature [5] [6] [7] [8]. It consists of treating a self-diagnosed disease without a medical prescription [9] [10]. This is generally limited to symptomatic treatments but sometimes to specific therapies such as anti-malarial drugs and antibiotics due to the informal distribution channels of these drugs. They are commonly known as "fake medicines" that are available at the market or in the street.

Resistance is one of the main consequences of self-medication [10] [11]. For several years, resistance to anti-malarial drugs has become a major concern and if its contributing factors are not controlled, and then, malaria cases management will become very difficult.

Benin, like most West African states, adopted the use of artemisinin-based combination therapies (ACTs) when revising its national strategic plan for fighting malaria in 2007 [12] in accordance with WHO recommendations of the same year [13]. However, several authors have noted that anti-malarial treatment failures are associated with resistance genes to ACTs, particularly dihydroartemisinin-piperaquine [14] [15] [16]. Although a recent study has shown that the situation is not yet very alarming in Benin [17], there is a need to con- 
trol drug resistance risk factors at the national level. Self-medication is the top-list factor and plays a key role in anti-malarial drug resistance. This is a well-known and growing phenomenon in African societies as evidenced in many literatures on the subject [18]-[22].

Despite the adoption by the National Malaria Control Program (NMCP) in 2011 of malaria confirmation strategy with at least a rapid diagnostic test before any anti-malarial therapy, many Beninese take anti-malarial drugs without any diagnostic confirmation. If difficult access to health facilities causes this practice, one may wonder whether the practice is so rare in our cities where health facilities and qualified health workers availability is acceptable. This work's purpose is to assess anti-malarial self-medication practice extent in the city of Parakou and to identify associated factors.

\section{Methods}

\subsection{Study Framework}

This study took place in 9 neighbourhoods in the 3 boroughs of Parakou city. These were precisely Albarika, Dépôt and Titirou for the $1^{\text {st }}$ borough, Banikanni, Nima-sokounon and Arafat in the $2^{\text {nd }}$ borough, then Zongo, Guêma and Tranza for the $3^{\text {rd }}$ borough.

\subsection{Type and Period of Study}

It was a descriptive cross-sectional analytical survey that took place from April 15 to June 24, 2017.

\subsection{Study Population}

The target population consisted of all the inhabitants of the nine neighbourhoods of Parakou city mentioned above.

\subsection{Selection Criteria}

\subsubsection{Inclusion Criteria}

Respondents should meet a number of criteria to be included. They should be 18 years of age or older, live in one of the nine selected neighbourhoods during the survey period, give their oral consent to participate in the survey and have had at least one episode of malaria during the last 6 months before the survey.

\subsubsection{Exclusion Criteria}

Health workers and pregnant women were excluded from this study.

\subsection{Sampling Technique}

This was a stratified probabilistic sampling. The minimum sample size calculated by the Schwartz formula with a 95\% confidence interval and an accuracy of 5\% was 237 respondents. They were recruited at least 27 respondents per neighbourhood. Three neighbourhoods were drawn lots in each of the three boroughs, making a total of nine neighbourhoods randomly selected out of 58 in 
the city of Parakou. Then, at the entrance of each neighbourhood, a pen rotation was used to determine the direction to follow. In this direction, households are systematically recruited. Within each household, simple random sampling was used to select only one respondent from those who met the inclusion criteria.

\subsection{Data Collection Techniques and Tools}

Data were collected using an individual survey sheet during a direct interview with each respondent. A pre-test questionnaire was carried out on fifteen randomly chosen respondents in a non-selected neighbourhood for the survey.

\subsection{Study Variables}

The dependent variable was anti-malarial self-medication. This consists of treating malaria by taking a drug without any medical prescription and regardless of the supply place. To purchase anti-malarial drugs in pharmacies in Benin there is no need to present a medical prescription, only the purchasing of drugs in pharmacy on the advice of a State-certified pharmacist was considered regulatory and not self-medication.

Independent variables were related to the sociodemographic, economic, clinical, therapeutic data, the drug dosage form, the supply place, the dosage, the distance from home to supply place, the distance from home to the nearest pharmacy and the nearest health facility, the respondents' perceptions of self-medication, the respondents' knowledge of self-medication risks.

\subsection{Data Processing and Analysis}

Data were entered and analysed using Epi-data 3.1 software. Variables frequency tables and graphs were made using Word and Excel version 2013 software. A bivariate analysis helped to examine the association between self-medication and the variables studied. For each variable studied, the proportion of respondents "having practiced anti-malarial self-medication" and "not practicing an anti-malarial self-medication" was calculated. Significant differences in proportions were tested using a Chi2 test or Fisher's exact test. Relative risks and their confidence interval were also calculated. Statistical analyses were performed with a $95 \%$ confidence interval. The significance threshold was set at $5 \%$.

\subsection{Ethical Considerations}

This study received the favourable opinion of the Ethics Committee for Biomedical Research of the University of Parakou. The oral consent of each respondent was obtained before using the questionnaire. A population survey authorization was obtained from the administrative authorities. Data collected in this study were treated anonymously and confidentially.

\subsection{Encountered Difficulties}

Language barrier was the main difficulty encountered during this survey. This 
difficulty is linked to the multitude of ethnic groups and dialects, which regularly requires a translator with the respondent's consent if conditions are met.

\section{Results}

\subsection{Study Flow}

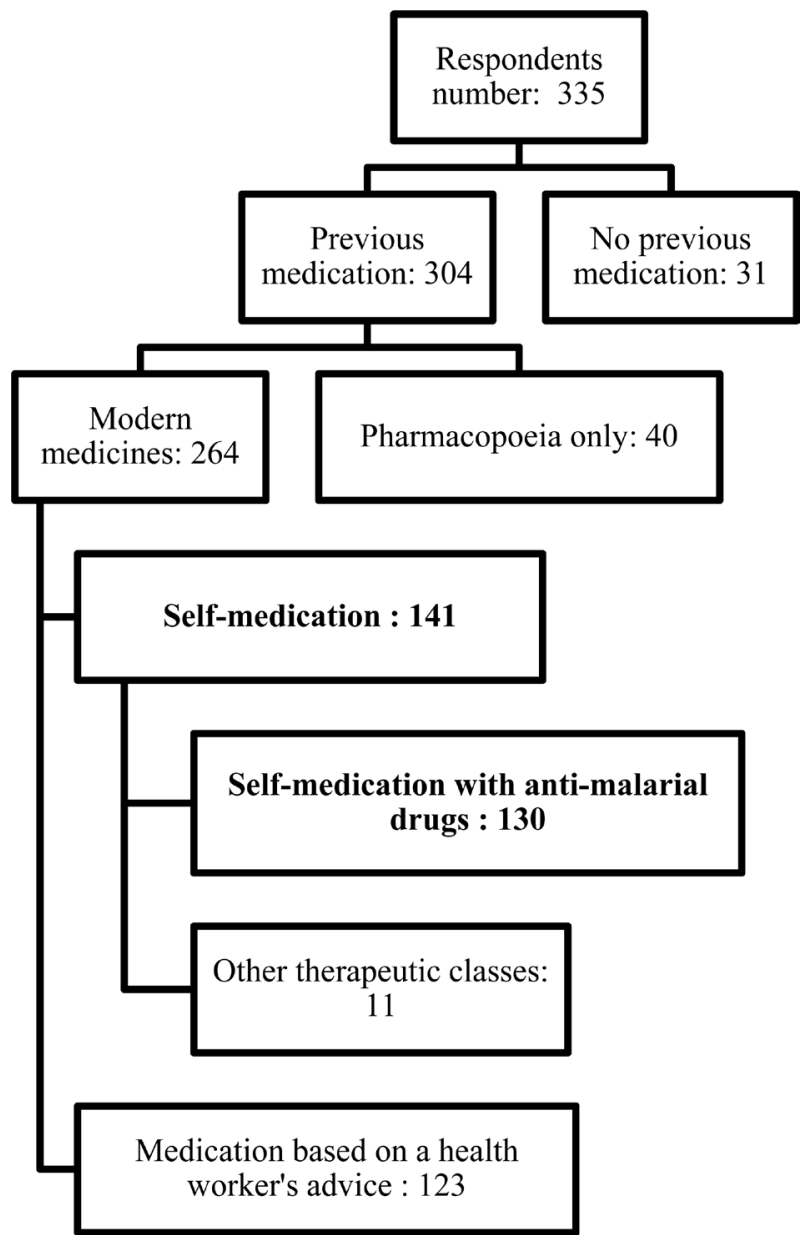

Figure 1. Study flow.

\subsection{Sociodemographic Characteristics}

A male predominance was noted with a sex-ratio of 1.4. The mean age was 29.69 \pm 12.11 years and more than $3 / 4$ of respondents had between 20 to 40 years old. By marital status, 183 were single (54.63\%) and 148 were married (44.18\%). Average monthly income was less than 70 US dollars in 243 respondents (72.54\%). Table 1 presents the sociodemographic characteristics of the respondents.

\subsection{Malaria Symptoms}

The main malaria symptoms cited by the respondents were fever $(129 \%$ or $38.51 \%)$, headache $(93 \%$ or $27.76 \%$ ), asthenia $(58 \%$ or $17.31 \%)$ and muscular aches and pains ( $30 \%$ or $8.96 \%)$. Table 2 presents the malaria symptoms cited by the respondents. 
Table 1. Socio-demographic characteristics of the respondents.

\begin{tabular}{|c|c|c|}
\hline Variables & Numbers & $\%$ \\
\hline \multicolumn{3}{|l|}{ Age } \\
\hline$<20$ years old & 35 & 10.45 \\
\hline 20 to 40 years old & 254 & 75.82 \\
\hline 40 to 60 years old & 34 & 10.15 \\
\hline$>60$ years old & 12 & 3.58 \\
\hline
\end{tabular}

\section{Gender}

$\begin{array}{lll}\text { Male } & 195 & 58.21\end{array}$

$\begin{array}{lll}\text { Female } & 140 & 41.79\end{array}$

\section{Schooling}

$\begin{array}{lll}\text { Not in school } & 41 & 12.24\end{array}$

Schooled

$\begin{array}{lcc}\text { Primary school } & 47 & 14.03 \\ \text { Secondary school } & 144 & 42.98 \\ \text { Superior } & 103 & 30.75\end{array}$

Profession

$\begin{array}{lll}\text { Craftsmen/Workers } & 93 & 27.76\end{array}$

$\begin{array}{lll}\text { Students/pupils } & 89 & 26.57\end{array}$

$\begin{array}{lll}\text { Trader } & 75 & 22.39\end{array}$

Farmers $\quad 45 \quad 13.43$

$\begin{array}{lll}\text { Civil servant } & 19 & 5.67\end{array}$

$\begin{array}{lll}\text { Housewife } & 14 & 4.18\end{array}$

Marital status

$\begin{array}{lcc}\text { Single } & 183 & 54.63 \\ \text { Married } & 148 & 44.18 \\ \text { Widowed } & 3 & 0.9 \\ \text { Divorced } & 1 & 0.3\end{array}$

Monthly income

$<70$ US dollars $\quad 243 \quad 72.54$

$>70$ US dollars $\quad 92 \quad 27.46$

Distance from home to the nearest health Centre (in meters)

$\begin{array}{lcc}<1000 & 195 & 58.21 \\ 1000-2000 & 121 & 36.12 \\ >2000 & 19 & 5.67\end{array}$

Distance from home to the nearest health Centre (in meters)

$\begin{array}{lcc}<1000 & 195 & 58.21 \\ 1000-2000 & 121 & 36.12 \\ >2000 & 19 & 5.67\end{array}$

Distance from home to the nearest pharmacy (in meters)

$\begin{array}{lcc}<1000 & 184 & 54.93 \\ 1000-2000 & 126 & 37.61 \\ >2000 & 25 & 7.46\end{array}$


Table 2. Main symptoms of malaria cited by the respondents.

\begin{tabular}{ccc}
\hline Main symptom & Number & $\%$ \\
\hline Fever & 129 & 38.51 \\
Headaches & 93 & 27.76 \\
Asthenia & 58 & 17.31 \\
Stiffness & 30 & 8.96 \\
Chills & 5 & 1.49 \\
Vomiting & 5 & 1.49 \\
Abdominal pain & 4 & 1.19 \\
Nasal discharge & 3 & 0.89 \\
Dark urine & 2 & 0.60 \\
Dizziness & 2 & 0.60 \\
Coughing & 2 & 0.60 \\
Anorexia & 1 & 0.30 \\
Icterus & 1 & 0.30 \\
\hline
\end{tabular}

\subsection{Self-Medication Frequency and Characteristics}

Of the 335 respondents considered in this study, 141 (42.09\%) practiced self-medication, including 130 (38.81\%) with anti-malarial drugs (Figure 1). For drugs used in self-medication, there were mainly 135 anti-malarial drugs (63.08\%), 71 antipyretics/analgesics (33.18\%), 5 antibiotics (2.34\%). Quinine (60\% or $44.45 \%)$ and ACTs ( $46 \%$ or $34.07 \%$ ) were the most used anti-malarial drugs followed by sulfadoxine-pyrimethamine (14\% or $10.37 \%)$ and chloroquine (3\% or $2.22 \%)$. Twelve respondents used "Api-palu", an anti-malarial drug manufactured in Benin. Table 3 shows the drugs used by the self-medication respondents and the supply places. Eighty-seven respondents (66.92\%) did not have a good knowledge of self-medication drugs dosage.

\subsection{Reasons for Self-Medication}

The reasons given to justify self-medication were mainly the high cost of consultation fees (99\% or $54.10 \%$ ), good knowledge of one's illness (53\% or $28.96 \%$ ) and easy access to medicines in pharmacies (20\% or 10.93\%) (Table 4 ).

\subsection{Associated Factors with Self-Medication}

Respondents were unaware of self-medication consequences. Only one respondent knew chemoresistance as a self-medication harmful consequence. Self-medication associated factors were fever $(\mathrm{p}=0.04)$, supply of non-prescription drugs in pharmacies $(\mathrm{p}<0.01)$, supply of drugs in informal market $(\mathrm{p}<0.01)$, previous satisfactory use of the drug $(\mathrm{p}<0.01)$, accessible cost of the drug $(\mathrm{p}=0.03)$ and drug recommendation by a relative or friend $(\mathrm{p}=0.02)$. 
Table 3. Drugs used in self-medication and sources of supply.

\begin{tabular}{|c|c|c|}
\hline Drugs and sources & Number & $\%$ \\
\hline Anti-malarial drugs & 135 & 63.08 \\
\hline Quinine & 60 & 44.45 \\
\hline ACT & 46 & 34.07 \\
\hline Sulfadoxine-pyrimethamine & 14 & 10.37 \\
\hline "Api-palu" & 12 & 8.89 \\
\hline Chloroquine & 3 & 2.22 \\
\hline Total & 135 & 100 \\
\hline Other medications & 79 & 36.92 \\
\hline Antipyretics/analgesics & 71 & 89.87 \\
\hline Antibiotics & 5 & 6.33 \\
\hline Vitamin supplements & 2 & 2.53 \\
\hline Wormers & 1 & 1.27 \\
\hline Total & 79 & 100 \\
\hline Total drugs used in self-medication & 214 & 100 \\
\hline \multicolumn{3}{|l|}{ Sources of supply } \\
\hline Pharmacy & 148 & 69.16 \\
\hline Informal market & 40 & 18.69 \\
\hline Remaining old stocks & 15 & 7.01 \\
\hline Supplied by entourage & 11 & 5.14 \\
\hline Total & 214 & 100 \\
\hline
\end{tabular}

"Api-palu" = antimalarial drug made in Benin. ACT = artemisinin-based combination therapy.

Table 4. Reasons for self-medication by respondents.

\begin{tabular}{lcc}
\hline \multicolumn{1}{c}{ Reasons given } & Number & $\%$ \\
\hline High cost of consultations & 99 & 54.10 \\
Good knowledge of one's illness & 53 & 28.96 \\
Easy access to medicines in pharmacies & 20 & 10.93 \\
Lack of time to go for consultation & 6 & 3.28 \\
Easy access to medicines in the informal market & 5 & 2.73 \\
Total & 183 & 100 \\
\hline
\end{tabular}

\section{Discussion}

This work's purpose was to study anti-malaria self-medication frequency and to identify its associated factors in the city of Parakou.

\subsection{Self-Medication Frequency for Treating Malaria with Adults in Parakou}

This study found $42.09 \%$ of adults living in Parakou routinely use self-medication when malaria is suspected. Houngnihin and al. noted that $88 \%$ of mothers first 
resorted to self-medication for fever in their children [9]. This confirms the entrenchment of such practice in Beninese population. Self-medication practice is very real in many other African countries. Its frequency was $91.4 \%$ among students in southwestern Nigeria in 2012 [20], 81\% in the northern district of Dakar in Senegal in 2006 [21], 65\% in Libreville, Gabon [22], 64.5\% in Ethiopia in 2003 [3] and 55.7\% in Cameroon in 2011 [5].

\subsection{Drugs Used in Anti-Malarial Self-Medication}

Quinine (60\% or $44.45 \%)$ and ACTs ( $46 \%$ or $34.07 \%)$ were the most used anti-malarial drug for self-medication among respondents. There is, therefore, a higher tendency to use quinine than CTAs. This could simply due to the lower cost of generic quinine compared to the cost of ACTs. Quinine is also a historically well-known medicine and remains widely used by the majority of Beninese population despite its side effects. Chloroquine has been used in self-medication although it is no longer recommended for preventive or curative treatment in Benin due to chemoresistance. Unfortunately, it continues to be sold in the informal market. Similarly, sulfadoxine-pyrimethamine, found in $10.37 \%$ of cases, is currently recommended in Benin only as intermittent preventive treatment in pregnant women. For this reason, pregnant women were excluded from this survey to avoid confusion. But perhaps they advise this medicine to other members of their family as a cure. It is also a cheaper drug and therefore easy to access which can justify its use. In all self-medication studies, there are almost the same drugs [3] [5] [23].

Seventy-one respondents (33.18\%) associated an antipyretic (paracetamol) with their medication. Malaria is a feverish disease, so this result is not surprising. Some patients often take only paracetamol delaying the use of care and promoting the disease evolution to complications. This finding was made by Diop and al. in Dakar in 2012 [24] and Metta and al. in Tanzania in 2014 [18].

In this study, antibiotics were also used as an anti-malarial self-medication drug. These are amoxicillin, ciprofloxacin and cotrimoxazole used to treat malaria. These medicines remain cheaper and more accessible in Benin regardless of the supply source. They can also be bought in pharmacies without any prescription. This facilitates their excessive and inappropriate use increasing thus the risk of resistance to these antibiotics. Many other studies mentioned antibiotics use in self-medication for treating malaria [3] [18] [19] [21] [22].

\subsection{Knowledge of Chosen Treatment Dosage and Its Duration}

Self-medication drugs dosage was inadequate in 87 respondents or $66.92 \%$ of cases. None of the respondents knew the normal duration of the treatment used in self-medication. There was a tendency to reduce the treatment dosage and duration. Not only this increases the resistance risk to anti-malarial drugs but also their sickness worsening risk in case of malaria. Yet $88.65 \%$ of self-medication respondents in this study were in school. Self-medication drugs misuse is well 
documented in the literature. Most of the time, the treatment respects neither the duration nor the recommended dose [3] [19] [21].

\subsection{Source of Medicines Supply}

Respondents obtained the drugs at three locations. Pharmacies came first, followed by the informal "street drugs" market. This is due to the non-prescription drugs dispensing in pharmacies and drugs sale in the informal sector despite numerous sensitizations to the population [8]. Indeed, a study conducted in Benin in 2015 noted that direct requests were so far the preferred way to buy medicines in pharmacies. While formal prescriptions were submitted by some clients, the majority of them were simple sheet of papers on which only the products' names were indicated. Others are served directly without any paperwork simply by explaining their symptoms to pharmacy staff who act as consultants and prescribers at pharmacies counter while they are not qualified for [8]. The sale of anti-malarial drugs in pharmacies without a medical prescription has been reported by several authors [8] [10] [11] [18] [19]. Fight against self-medication must include the regulation of prescription drugs sale in pharmacies on the one hand, and the fight against "false drugs" on the other hand.

\subsection{Factors Associated with Self-Medication in Malaria Treatment}

Factors associated with self-medication were fever $(\mathrm{p}=0.04)$, the supply of non-prescription drugs in pharmacies $(\mathrm{p}<0.01)$, the drugs supply in the neighbourhood ( $p<0.01$ ), the satisfaction history use of the drug $(\mathrm{p}<0.01)$, accessible cost of the drug $(\mathrm{p}=0.03)$ and drug recommendation by a relative or friend $(p=0.02)$.the distance between the respondent's home and the nearest health centre was not a factor associated with self-medication in this study as was the case in a Ugandan study [6]. And only a minority of self-medicated respondents (4.26\%) lived more than $2 \mathrm{~km}$ from the nearest health centre.

These factors could be the consequence of the respondents' low purchasing power. The main reason given by respondents for self-medication was the high cost of consultation and medical care in health facilities. Therefore, to get around this difficulty they go directly to pharmacies or market to access drugs. Establishing a universal health insurance system could improve attendance to health facilities and significantly reduce the use of self-medication among population.

\section{Conclusion and Recommendations}

At the end of this study, we can conclude that anti-malarial self-medication is a common and frequent practice in the city of Parakou. Quinine and artemisinin-based combination therapies are most commonly used with inappropriate dosage in the majority of cases. Over-the-counter sale of medicines in pharmacies and the availability of street medicines, added to the low purchasing power of the respondents, are the main factors favouring self-medication. The fight against this scourge must include the establishment of a universal health insur- 
ance system, the subordination of the distribution of essential drugs in pharmacies to the presentation of a medical prescription, the fight against "fake drugs" and "street drugs" coupled with public awareness.

\section{Ethics Approval and Consent to Participate}

This study received the favourable opinion of the local ethics committee for biomedical research of the University of Parakou (CLERB-UP). All participants in this study provided their oral, free and informed consent before responding to the questionnaires. They were not under any pressure throughout the investigation.

Consent for publication: The respondents also gave no objection to the publication of data from this survey.

\section{Acknowledgements}

We thank all investigators and administrative authorities at various levels who facilitated this survey, as well as Sophie ONIDJE for her contribution to the translation of the manuscript and Mathias Hounnou AZOUA for the re-read of the translated version of the manuscript.

\section{Funding}

This work did not receive any external funding.

\section{Authors' Contributions}

CAA initiated the study. CAA and MS wrote the study protocol. DMZ and all other co-authors contributed to the validation of the study protocol. MS conducted the survey and data analysis under the supervision of CAA and DMZ. CAA and YS wrote the article. EA and AA re-read the article.

\section{Conflicts of Interest}

The authors declare no conflicts of interest regarding the publication of this paper.

\section{References}

[1] World Health Organisation (2018) World Malaria Report. WHO, Geneva, 210 p. https://www.who.int/malaria/media/world-malaria-report-2018/fr/

[2] WHO (2015) Stratégie technique mondiale de lutte contre le paludisme 2016-2030. WHO, Geneva, 36 p. https://www.who.int/malaria/publications/atoz/9789241564991/fr/

[3] Deressa, W., Ali, A. and Enqusellassie, F. (2003) Self-Treatment of Malaria in Rural Communities, Butajira, Southern Ethiopia. Bulletin of the World Health Organization, 81, 261-268.

[4] Institut National de la Statistique et de l'Analyse Économique (INSAE) et ICF (2018) Enquête Démographique et de Santé au Bénin, 2017-2018: Indicateurs Clés. Cotonou, INSAE et ICF, Bénin et Rockville, MD. 
[5] Nsagha, D.S., Njunda, A.L., Kamga, H.L.F., Nsagha, S.M., Assob, J.C.N., Wiysonge, C.S., et al. (2011) Knowledge and Practices Relating to Malaria in a Semi-Urban Area of Cameroon: Choices and Sources of Antimalarials, Self-Treatment and Resistance. Pan African Medical Journal, 9, 8. https://doi.org/10.4314/pamj.v9i1.71180 http://www.panafrican-med-journal.com/content/article/9/8/full/

[6] Ocan, M., Bwanga, F., Bbosa, G.S., Bagenda, D., Waako, P., Ogwal-Okeng, J., et al. (2014) Patterns and Predictors of Self-Medication in Northern Uganda. PLoS ONE,

9, e92323. https://doi.org/10.1371/journal.pone.0092323

[7] Chipwaza, B., Mugasa, J.P., Mayumana, I., Amuri, M., Makungu, C. and Gwakisa, P.S. (2014) Self-Medication with Anti-Malarials Is a Common Practice in Rural Communities of Kilosa District in Tanzania Despite the Reported Decline of Malaria. Malaria Journal, 13, Article No. 252.

https://doi.org/10.1186/1475-2875-13-252

[8] Djralah, M., Agossou, A., Kpatinvoh, A. and Baxerres, C. (2015) Automédication et recours aux acteurs privés et informels de la distribution détaillante au Bénin. In: Actes des Rencontres Nordl Sud de l'automédication et de ses déterminants. Cotonou (Bénin). IRD, UAC, UN, 55-63.

[9] Houngnihin, A. (2015) Écart entre recommandations officielles et pratiques effectives: éléments d'analyse de l'automédication en cas de fièvre en milieu rural à Dassa-Zoumé. In: Actes des Rencontres Nordl Sud de Pautomédication et de ses déterminants, GlobalMed, Dassa-Zoumé (Bénin), 204-211.

[10] Fainzang, S. (2010) L'automédication: Une pratique qui peut en cacher une autre. Anthropologie et Sociétés, 34, 115-133. https://doi.org/10.7202/044199ar

[11] Foster, S.D. (1999) Pricing, Distribution, and Use of Antimalarial Drugs. Bulletin of the World Health Organization, 69, 349-363.

[12] Programme national de Lutte contre le Paludisme au Bénin (2007) Plan stratégique nationale de lutte contre le paludisme 2006-2010. Cotonou, PNLP, 96 p. http://portedoc.aucoeurdeshommes.org/files/Public/Informations\%20Benin/palu\% 20benin.pdf

[13] World Health Organization (2007) World Health Assembly Resolution 60.18 (WHA60.18). https://www.who.int/tdr/about/governance/documents/WHA60.18.pdf

[14] Witkowski, B., Duru, V., Khim, N., Ross, L.S., Saintpierre, B., Beghain, J., Chy, S., Kim, S., et al. (2016) A Surrogate Marker of Piperaquine-Resistant Plasmodium Falciparum Malaria: A Phenotype-Genotype Association Study. The Lancet Infectious Diseases, 17, 174-183. https://doi.org/10.1016/S1473-3099(16)30415-7

[15] Amato, R., Lim, P., Miotto, O., Amaratunga, C., Dek, D., Pearson, R.D., et al. (2016) Genetic Markers Associated with Dihydroartemisinin-Piperaquine Failure in Plasmodium falciparum Malaria in Cambodia: A Genotype-Phenotype Association Study. The Lancet Infectious Diseases, 17, 164-173.

https://doi.org/10.1016/S1473-3099(16)30409-1

[16] Amaratunga, C., Lim, P., Suon, S., Sreng, S., Mao, S., Sopha, C., Sopha, C., Sam, B., et al. (2016) Dihydroartemisinin-Piperaquine Resistance in Plasmodium falciparum Malaria in Cambodia: A Multisite Prospective. The Lancet Infectious Diseases, 16, 357-365. https://doi.org/10.1016/S1473-3099(15)00487-9

[17] Ogouyemi-Hounto, A., Azandossessi, C., Lawani, S., Damien, G., Savi de Tove, Y., Remour, F. and Kinde Gazard, D. (2016) Therapeutic Efficacy of ArtemetherLumefantrine for the Treatment of Uncomplicated Falciparum Malaria in Northwest Benin. Malaria Journal, 15, Article No. 37. https://doi.org/10.1186/s12936-016-1091-2

[18] Metta, E., Haisma, H., Kessy, F., Hutter, I. and Bailey, A. (2014) "We Have Become 
Doctors for Ourselves": Motives for Malaria Self-Care among Adults in Southeastern Tanzania. Malaria Journal, 13, Article No. 249.

https://doi.org/10.1186/1475-2875-13-249

https://malariajournal.biomedcentral.com/articles/10.1186/1475-2875-13-249

[19] Ocan, M., Obuku, E.A., Bwanga, F., Akena, D., Richard, S., Ogwal-Okeng, J. and Obua, C. (2015) Household Antimicrobial Self-Medication: A Systematic Review and Meta-Analysis of the Burden, Risk Factors and Outcomes in Developing Countries. BMC Public Health, 5, Article No. 742. https://doi.org/10.1186/s12889-015-2109-3

[20] Osemene, K. and Lamikanra, A. (2012) A Study of the Prevalence of Self-Medication Practice among University Students in Southwestern Nigeria. Tropical Journal of Pharmaceutical Research, 11, 683-689. https://doi.org/10.4314/tjpr.v11i4.21

[21] Ndiaye, P., Tal-Dia, A., Diedhiou, A., Juergens-Behr, A. and Lemort, J. (2006) L'automédication de la fièvre dans le district nord de Dakar au Sénégal. Medecine Tropicale, 66, 74-78.

[22] Perret, J. and Ngomo, M. (1993) Automédication antipalustre chez les adultes consultant pour fièvre au Centre hospitalier de Libreville. Médecine d Afrique Noire Electronique, 40, 522-524.

[23] Awad, A., Eltayeb, I., Matowe, L. and Thalib, L. (2005) Self-Medication with Antibiotics and Antimalarials in the Community of Khartoum State, Sudan. Journal of Pharmacy and Pharmaceutical Sciences, 8, 326-331.

[24] Diop, S.A., Attinsounon, C.A., Fortes-Déguénonvo, L., Cisse Diallo, V.M.P. and Seydi, M. (2014) Therapeutic Itinerary of Severe Malaria in Adults Admitted to a Teaching Hospital in Dakar, Senegal. The Journal of Infection in Developing Countries, 8, 1353-1355.

\section{List of Abbreviations}

WHO $=$ World Health Organization

$\mathrm{NMCP}=$ National Malaria Control Program

$\mathrm{ACT}=$ Artemisinin-Based Combination Therapy 